\title{
Transient Flow Modeling and Verification of a 20-MGD Raw Water Conveyance System
}

\author{
Srinivasan Sundaramoorthy
}

Transient flow conditions in a closed pipe system refer to the change in steady-state conditions that occur as a result of planned or unexpected operational changes. These changes typically result in undesirable pressure fluctuations in the pipe that could result in catastrophic failure or increased operation and maintenance costs unless the system is adequately designed to handle these phenomena. The analysis of transient flow conditions is somewhat complex and requires specialized understanding of the system behavior. With the advancement in the computer speed and software technology, user friendly transient flow analysis software is now available to model the transient behavior in pipe network and establish design parameters to adequately protect the system.

This chapter presents the hydraulic and transient modeling of the Skiatook Raw Water Conveyance System (SRWCS), surge model calibration using field data, and post improvement verification of the computed performance. Surge $2000^{\circ}$ software was used in the analysis. In addition, this chapter also discusses how hydraulic modeling was effectively used in establishing additional raw water storage that results in considerable savings in pumping energy cost.

The SRWCS is jointly owned by the cities of Sapulpa and Sand Springs to convey raw water from Lake Skiatook to their respective treatment facilities. The cities of Sapulpa and Sand Springs are located just west of

Sundaramoorthy, S. 2006. "Transient Flow Modeling and Verification of a 20-MGD Raw Water Conveyance System." Journal of Water Management Modeling R225-14. doi: 10.14796/JWMM.R225-14.

(C) CHI 2006 www.chijournal.org ISSN: 2292-6062 (Formerly in Intelligent Modeling of Urban Water Systems. ISBN: 0-9736716-2-9) 
Tulsa, Oklahoma, and the Lake Skiatook is located northwest of Tulsa. This system was originally completed in 1992 and included a strainer building, a pump station and approximately 24 miles of 36- and 24-inch raw water transmission lines and storage. The original pump station included four vertical turbine pumps $75 \mathrm{hp}, 200 \mathrm{hp}, 400 \mathrm{hp}$ and $600 \mathrm{hp}$, respectively. To meet increased demand, the pump station was upgraded in 2002 that included replacement of the smallest pump with a new 1250-hp, 15 million gallons per day (mgd) pump and improvements to the strainer and surge control systems. The transient analysis was performed as part of this upgrade.

\subsection{Overview of Transient Flow in Closed Pipe}

\subsubsection{What is Transient Flow?}

Water hammer or surge in closed pipe flow refers to the transient hydraulic phenomena that occur due to change in steady-state conditions. The magnitude of response to these flow variations depends directly on how rapidly the change is induced and how effectively the system is protected against such change. "Surge" typically refers to relatively slow changes in flow, whereas, "hammer" refers to more rapid changes in flow or velocity".

The pressure surge is analogous to a freight train. Consider a 24-inch $(600 \mathrm{~mm})$ diameter pipe 1 mile long $(1.61 \mathrm{~km})$ flowing at a steady state velocity of $5 \mathrm{ft} / \mathrm{s}(5.5 \mathrm{~km} / \mathrm{h})$. The mass of water in the pipeline is approximately $1,040,000$ pounds $(472,000 \mathrm{~kg})$. Similar to a freight train, in order to change the velocity, a force is required. On the contrary, change in velocity results in a force which gives rise to the pressure surge.

The pressure rise in a closed pipe due to velocity change is given by the following equation originally developed by Joukowski ${ }^{2}$ :

$$
\Delta \mathrm{H}=\frac{\mathrm{a}}{\mathrm{g}} \Delta \mathrm{V}
$$

were:

$$
\begin{aligned}
\Delta H & =\text { Surge pressure, } \mathrm{ft} \text { or } \mathrm{m} \text { of water } \\
\mathrm{A} & =\text { Pressure wave velocity, } \mathrm{ft} / \mathrm{s} \text { or m/s } \\
\mathrm{g} & =\text { Acceleration due to gravity, } 32.17 \mathrm{ft} / \mathrm{s}^{2} 9.81 \mathrm{~m} / \mathrm{s}^{2} \\
\Delta V & =\text { Fluid velocity change, } \mathrm{ft} / \mathrm{s} \text { or } \mathrm{m} / \mathrm{s}
\end{aligned}
$$


Equation 14.1 is somewhat simplistic in that it does not consider the effect of pipe friction or the pipe wall deformation. Actual pressures may be substantially more due to pipe friction or the formation vapor cavities or both $^{2}$. Rule of thumb pressure rise for a unit change in velocity for various pipe materials is summarized in Table 14.1.

Table 14.1 Rule of thumb pressure rise in pipe.

\begin{tabular}{|c|c|c|c|}
\hline \multirow[t]{2}{*}{ Pipe Material } & \multirow[t]{2}{*}{$\begin{array}{l}\text { Wave Velocity } \\
\text { fps }(\mathrm{m} / \mathrm{s})\end{array}$} & \multicolumn{2}{|c|}{$\begin{array}{c}\text { Pressure Rise per } 1 \text { fps or } 1 \\
\mathrm{~m} / \mathrm{s} \\
\text { Velocity Change }\end{array}$} \\
\hline & & Psi & $\mathrm{kPa}$ \\
\hline A/C Transite & $\begin{array}{l}2400-3500 \\
(730-1100)\end{array}$ & 35 & 241 \\
\hline CI (AWWA C-101) & $\begin{array}{l}3000-5000 \\
(900-1500)\end{array}$ & 55 & 379 \\
\hline DI (AWWA C-150) & $\begin{array}{l}3000-5000 \\
(900-1500)\end{array}$ & 50 & 345 \\
\hline PVC (AWWA C-900) & $\begin{array}{c}1200-1500 \\
(360-460\end{array}$ & 20 & 138 \\
\hline
\end{tabular}

Reference 1. Values shown are rounded.

From Equation 14.1 it is evident that the pressure rise is directly proportional to the wave velocity and the magnitude of velocity change. The wave velocity in turn is a function of fluid density, fluid bulk modulus, pipe diameter, pipe wall thickness, and the modulus of elasticity of the pipe material. Transient pressure is a wave phenomenon. The pressure rise (up surge) is accompanied by pressure drop (down surge). If the pressure drops below the vapor pressure of the liquid, vapor cavity and water column separation can result. As the pressure drops, initially dissolved gases are released from the liquid phase. As the pressure drops further below the vapor pressure of the liquid, the liquid "boils" and change into vapor phase. The collapse of vapor cavity from returning water column can result in extremely high pressures and very unstable conditions in a pipeline.

With the advent of personal computers with high speed processors, user friendly software is now available to solve transient flow in closed pipes. These computer programs utilize numerical algorithms to mathematically solve for velocity and pressures along the pipeline for a given boundary 
condition. Surge $2000^{\circledR}$ software developed by KY Pipe, LLC was used for the analysis discussed in this chapter.

\subsubsection{Causes of Transients in Closed Pipe Flow}

Flow in a closed pipe is never steady-state, but in most normal situations, the changes are relatively small to cause any serious effect. However, changes that occur as a result of certain equipment operations or emergency situations can result in considerable pressure rise or in vapor cavities. Typically, transients in pipelines are cause by (i) normal pump startup/shutdown, (ii) emergency power failure (iii) rapid changes in demand, and (iv) rapid closure of valves.

During normal pump startup, certain momentum is needed to initiate fluid movement from rest. When the pump is started with down stream void space (during line filling), the collapse of downstream void, if not controlled properly, can create an undesirable pressure conditions. Similarly, during normal pump shutdown, the pump spins down to rest rapidly but the liquid flow on the discharge side continues to move away from the pump causing a 'down surge' condition that can result in pressure drop and potentially vapor cavities to form. Emergency power failure creates a similar condition to pump shutdown. Rapid demand changes can cause undesirable transients. For example, when multiple hydrants are opened rapidly the resulting velocity change can cause undesirable pressures in the distribution system.

\subsection{Skiatook Raw Water Conveyance System (SRWCS)}

\subsubsection{SRWCS System Description}

The SRWCS is jointly owned by the cities of Sapulpa and Sand Springs to convey raw water from Lake Skiatook to their respective treatment facilities. This system was originally completed in 1992 and included a strainer building, a pump station storage tank and the conveyance lines. Figure 14.1 is a schematic representation of the SRWCS system.

Raw water flows by gravity from the Skiatook Lake via a 36-inch $(900 \mathrm{~mm})$ ductile iron pipe to the pump station. At the pump station there are two strainers in parallel that remove solids and debris greater than $5 / 32$ inches $(4 \mathrm{~mm})$. There are four vertical turbine pumps located 
downstream of the strainers (Figure 14.2) that discharge via approximately 18 -miles $(29 \mathrm{kms}) 36$-inch and 6-miles $(9.8 \mathrm{kms})$ of 24 -inch $(600 \mathrm{~mm})$ prestressed concrete steel cylinder pipes (PCCP) to the respective cities. The ground relief along the pipe line varies as much as $300 \mathrm{feet}(90 \mathrm{~m})$.

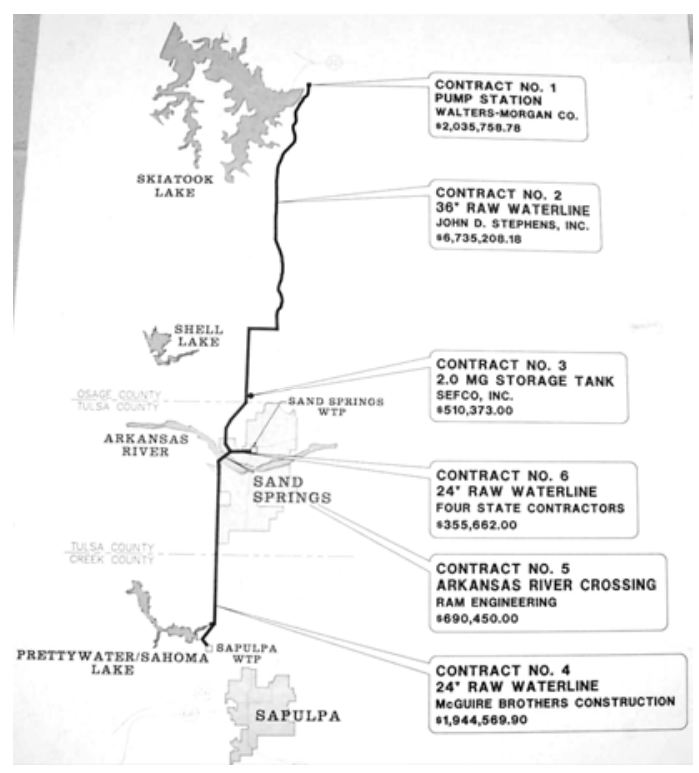

Figure 14.1 SRWCS schematic representation.

The existing primary surge control system consists of the closed surge arrestor tank located at the pump station, the one-way tank located approximately 3 miles $(4.9 \mathrm{kms})$ downstream of the pump station, and the 2-mg $\left(7,580 \mathrm{~m}^{3}\right)$ tank located at the high point in the system at approximately 15 miles $(24 \mathrm{~km})$ downstream of the pump station. In addition, there are combination air/vacuum release valves located at key elevations along the transmission line. These valves help to discharge air during line filling as well as to allow atmospheric air to enter the line in cases of vacuum condition.

The surge arrestor tank was furnished by Pulsco of Santa Ana, California. It is a hydro-pneumatic air charge over water pressure vessel used to control adverse pressure transient in the pipeline. During pump shut down or emergency trip, the pressure in the main line downstream of the 
pump discharge valve begins to decrease. The compressed air in the tank expands to force water into the pipeline. As the flow reverses, it counters a closed check valve and the flow energy is converted into a pressure rise. This increased pressure forces the flow into the surge arrestor compressing the air charge. A combination of air compression and energy dissipation assembly within the arrestor controls the maximum pressure rise in the main line and reduces the magnitude and number of oscillations of the pressure wave. During pump startup, the pressure in the main line starts to increase and forces water into the surge arrester compressing the air stored in the tank. The pressure in the tank is slightly higher than the steady-state pressure, and the system starts to adjust by accelerating water away from the pump. This cycle continues until the steady-state pressure is reached. The surge arrestor is provided with level controls and an air source so the water in the tank is maintained to a minimum level to prevent air from escaping into the pipeline.

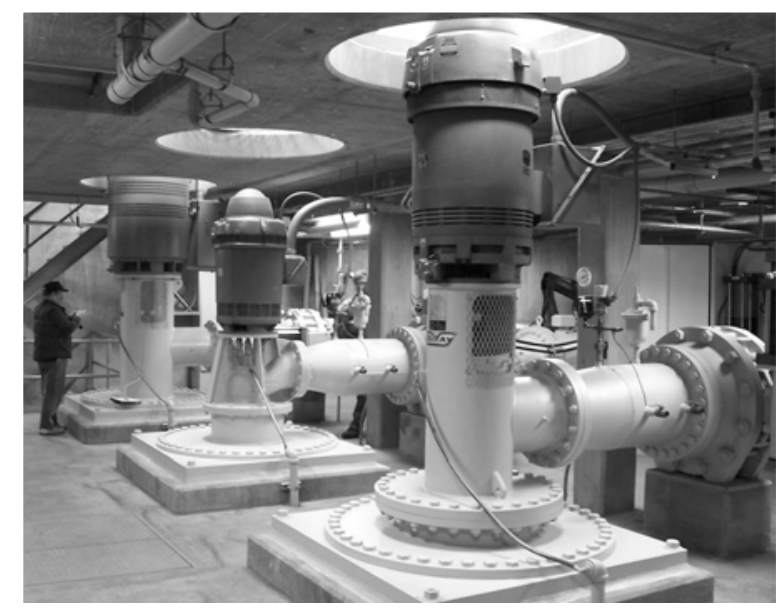

Figure 14.2 Vertical turbine pumps.

The one-way tank (Figure 14.3) is approximately 20 -foot $(6 \mathrm{~m})$ diameter by 20 -foot tall steel tank that is connected to the main line by a 24 -inch line. The 24-inch line has both a one-way altitude valve and a one-way check valve. The one-way altitude valve allows flow into the tank for filling. Any time the main line pressure drops below the tank head, the check valve 
allows flows from the tank into the main line to prevent formation of vacuum and vapor cavities.

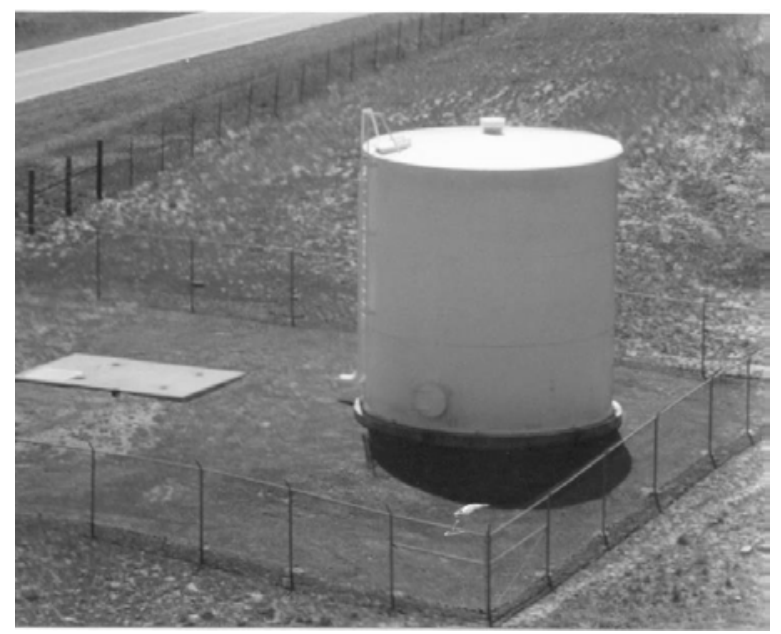

Figure 14.3 One-way surge tank.

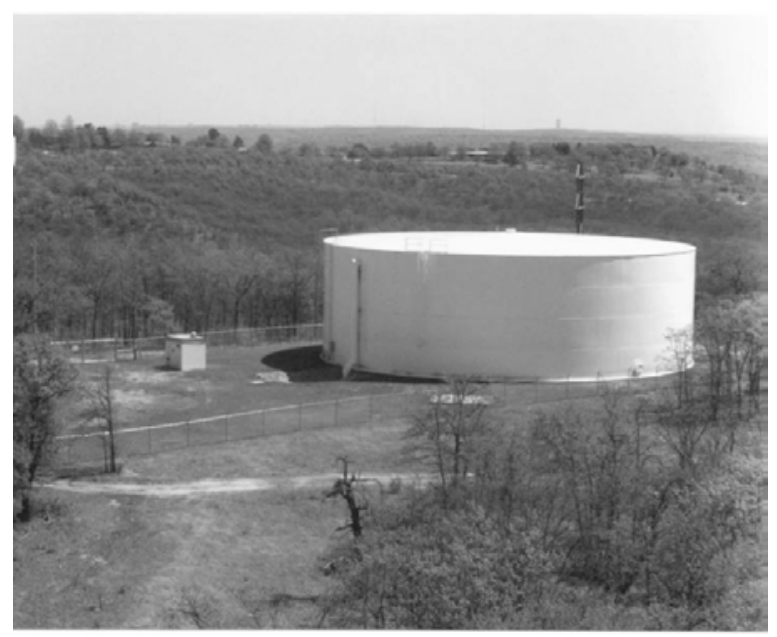

Figure 14.4 2-MG storage tank. 
The 2-mg tank (Figure 14.4) serves as the system storage and provides the necessary level controls for the pump's operation. In addition, this tank also provides volume flow into the main line during pressure transient.

\subsubsection{Project Goals}

The original pump station design included four steel-cans which were originally oversized to accommodate larger pumps for future. The original configuration included four vertical turbine pumps $75 \mathrm{hp}(56 \mathrm{~kW}), 200 \mathrm{hp}$ $(149 \mathrm{~kW}), 400 \mathrm{hp}(299 \mathrm{~kW})$, and $600 \mathrm{hp}(448 \mathrm{~kW})$. The station had a total capacity of approximately $12 \mathrm{mgd}\left(45,500 \mathrm{~m}^{3} / \mathrm{d}\right)$. Because of increased system demand, the station capacity was upgraded in 2002 . The project goal was to establish the replacement pump size and to verify the adequacy of the existing surge control system for the increased flow condition. The following is a discussion of the modeling and the analysis of results.

\subsubsection{System Modeling}

In the 2002 analysis, Surge 5 software was used to model and analyze the system. Surge 5 was developed by KY Pipe, LLC. Surge 5 has since been replaced by Surge $2000^{9}$ Windows version, which was used to recreate the results for this chapter.

Figure 14.5 is a representation of the SRWCS Surge model. The computer model is constructed by a series of junction nodes, pipe links, pumps and other system components to reasonable reflect the existing system. With the advent of high speed processors and efficient algorithms, skeletonizing is not necessary from calculation time stand point. However, in surge modeling, short pipe segments can cause some instability and cause errors. There is no hard and fast rule in this regard. The authors experience has been to construct the model to represent the existing system layout as closely as possible. If initial runs indicate short pipe segments is the cause for instability, then use engineering judgment to simplify the network.

Constructing surge model is similar to the hydraulic steady state model except that additional parameters are needed to define the system. These additional parameters include wave velocity in pipes, pump speedup/shutdown characteristics, check valve closure time and the surge control device parameters. First, steady state analysis was performed to establish the pump size. Once the steady state condition is established, a surge analysis was performed as discussed below. 


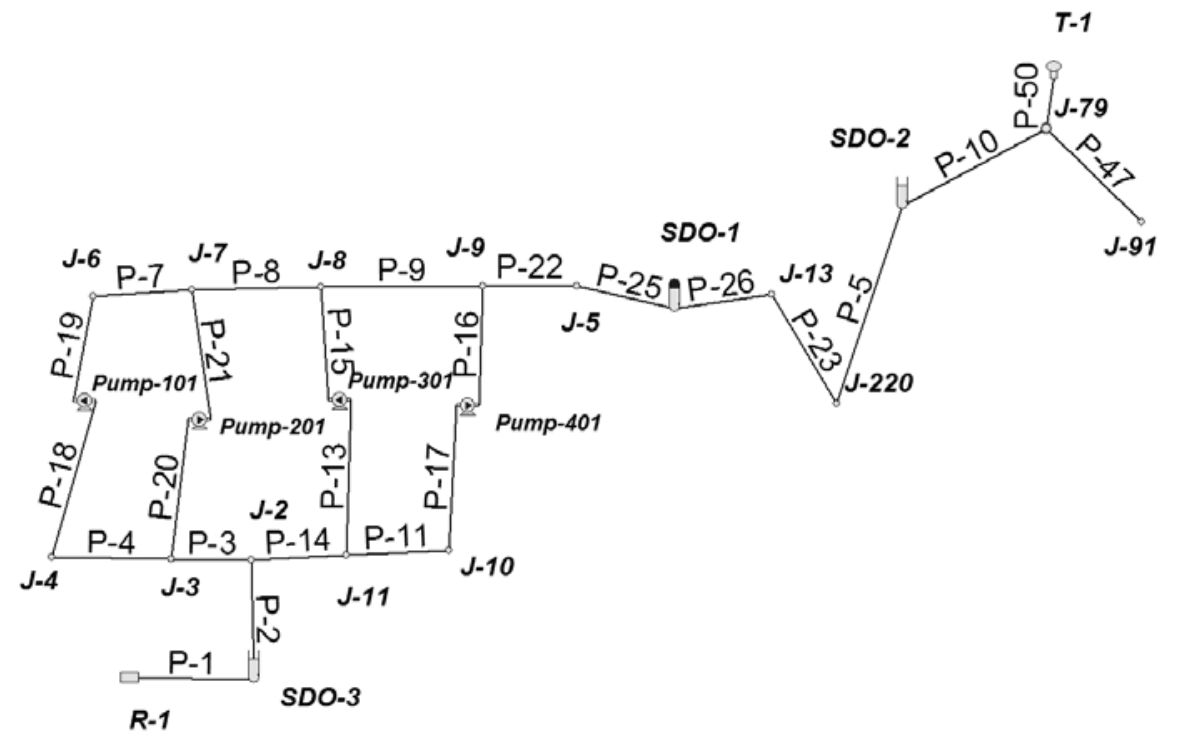

Figure 14.5 Surge Network Model.

\subsubsection{Steady State Analysis}

This analysis focused on steady state hydraulics where the fluid momentum was not considered. First, the model was calibrated using known system conditions (measured in the field) such as tank levels, pump station flows, suction and discharge pressures to assure the model simulated the system performance reasonably. Calibration involved utilizing the observed values (flow and pressures) and adjusting the pipe friction values and pump flowhead characteristics so the computed results matched reasonably with the observed results (within 7\%). The adjusted friction values (C-factor) were approximately 120 which are reasonable for the age and condition of the pipe. In order to obtain a total capacity of $20 \mathrm{mgd}$, the smallest existing pump would have to be replaced with a larger pump, 1,250 hp (943 kW) with a capacity of $15 \mathrm{mgd}\left(56,800 \mathrm{~m}^{3} / \mathrm{d}\right)$. The existing pump barrel was large enough to accommodate this pump. This new pump along with other existing pumps was used in the subsequent surge analysis to evaluate the surge control system. 


\subsubsection{Surge Analysis}

First, a calibration of the surge model was performed. In order to gather system performance data for model calibration, an actual pump station startup was monitored. A normal startup followed by power failure trip was conducted in 2001 and pump discharge pressure was recorded using a Telog Model HPR-21 pressure data logger. Discharge pressure was sampled and logged at $1 \mathrm{~s}$ interval. The data was exported to a spreadsheet for plotting and comparison purposes. Figure 14.6 shows the comparison of model results with the actual field observed data when two largest existing pumps (400 hp and $600 \mathrm{hp}$ ) were tripped. The surge model calibration involved adjusting the pipe wave speed and the control device coefficients so the model results reasonably matched the observed results. As shown in Figure 14.6, the steady state discharge pressure, upon pump trip, dropped from approximately $165 \mathrm{psi}(1139 \mathrm{kPa})$ to approximately $110 \mathrm{psi}(758 \mathrm{kPa})$ and then bounced backed to reach a steady state pressure of about $150 \mathrm{psi}$ $(1034 \mathrm{kPa})$ in approximately 8 to 10 minutes.

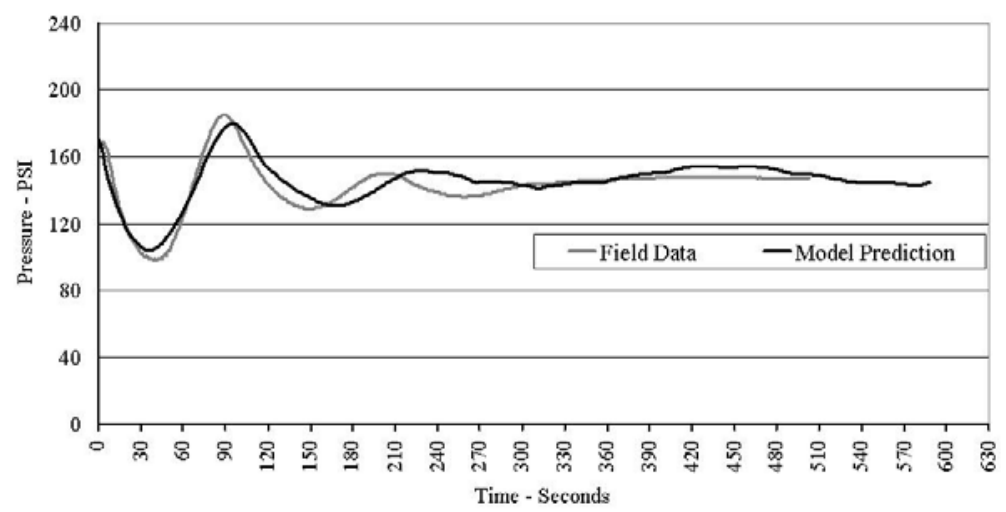

Figure 14.6 Surge analysis calibration- $400 \mathrm{hp}$ and $600 \mathrm{hp} \mathrm{pump} \mathrm{trips.}$

The calibrated model was used to evaluate the system performance with the new $1250 \mathrm{hp}$ pump. The surge analysis indicated that the existing surge control system was adequate to accommodate the new large pump. However, the level control setting for the surge arrestor needed to be changed to accommodate the larger pump. This required the surge arrestor manufacturer Pulsco to remove the existing six level probes and replacing 
them with a longer length to accommodate the new level settings. After the pump was installed, post improvement verification was performed by the contractor. Figure 14.7 shows the comparison of the $1250 \mathrm{hp}$ pump trip with the actual field pressures compared with the model simulated results. The pressure fluctuations matched extremely well thus verifying the calibrated model. One observation that could be made in both Figure 14.6 and 14.7 is the actual wave period observed in the field has a shorter duration than computed by the model. Errors in the pipe length or the wave velocity were ruled out since the pipe lengths were based on record drawings information and the pressure peaks match reasonably well indicating the wave velocity was appropriate. One possible reason is that the surge arrestor tank has internal baffles which dissipated the energy. Another possible explanation is that the many bends in the actual line alignment tend to reflect the waves, the cumulative effect of which is to shorten the overall wave periods. The effects were not modeled due to time constraints and the fact that the primary focus was to evaluate the system surges pressures peaks which was met in the study.

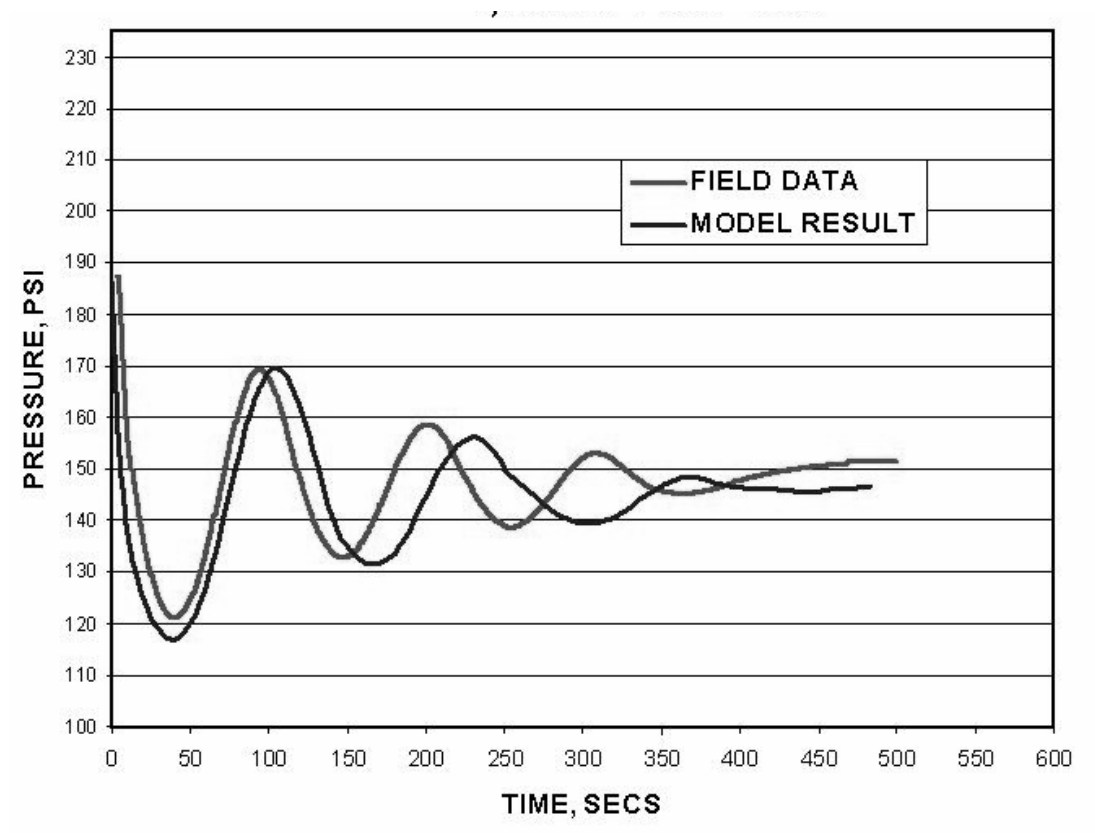

Figure 14.7 Results comparison $1250 \mathrm{hp} \mathrm{pump} \mathrm{trip.}$ 
The Surge program is also capable of producing hydraulic grade envelop along the pipeline. Figure 14.8 shows the grade envelope (in feet) along the pipe alignment. This helps to visually verify that the line pressures remain above atmosphere during the surge event.

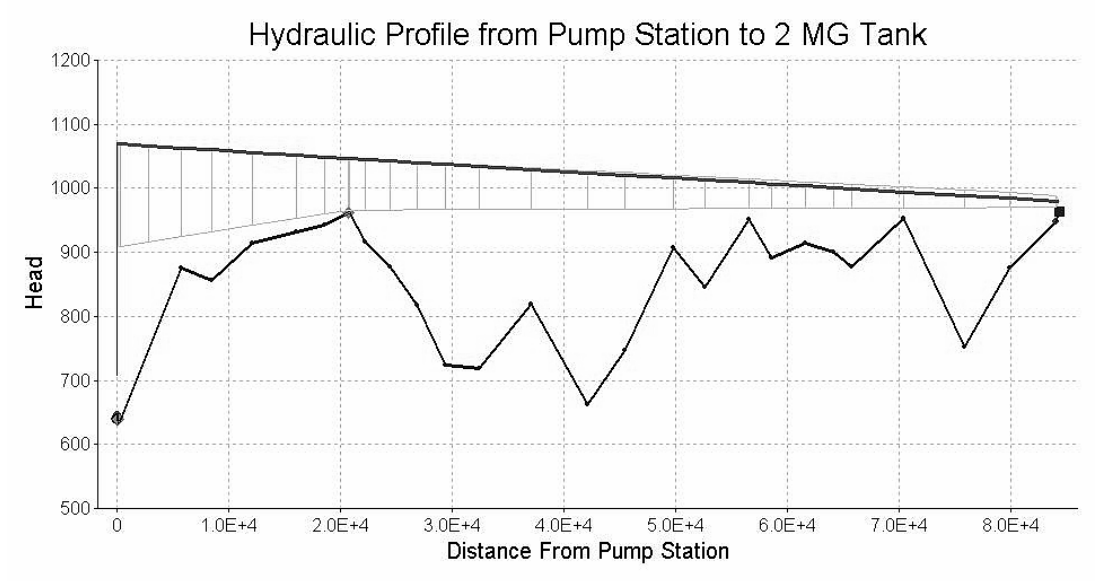

Figure 14.8 Hydraulic grade envelope.

\subsubsection{Additional Storage for Energy Savings}

In a water conveyance system, pumping cost constitutes a large portion of the operation and maintenance (O\&M) costs. Power companies typically impose a usage charge and a demand charge. The demand charges are set to discourage usage during peak usage times and are typically many times higher than the normal usage charge. For the SRWCS, the demand charge is based on maximum energy usage during the afternoon hours of 2:00 pm to 7:00 pm between the months of June through September. Especially with large pumps, the time of operation becomes very critical in minimizing the very regressive peak demand charges.

Computer hydraulic analyses (extended period simulation) are extremely valuable in evaluating various pumping schemes with additional storage to meet the system demand while minimizing pumping during periods of peak electrical usage. Figure 14.9 shows such an analysis for the SRWCS system. Without the additional storage the full demand is met by pumping alone which resulting in higher $\mathrm{kW}$ usage during the peak demand period. 
However, with the additional $2 \mathrm{MG}$ storage, the stored volume will supplement the pumping thereby resulting in reduced $\mathrm{kW}$ usage during the peak usage period. The projected savings in demand charges alone over a 20 -year period is approximately $\$ 550,000$, which almost pays for the cost of the new tank. It is noted that additional storage does not reduce the total pumping energy but the cost of energy. 2 MG Volume was found to be the optimum based on existing site layout and project phasing.

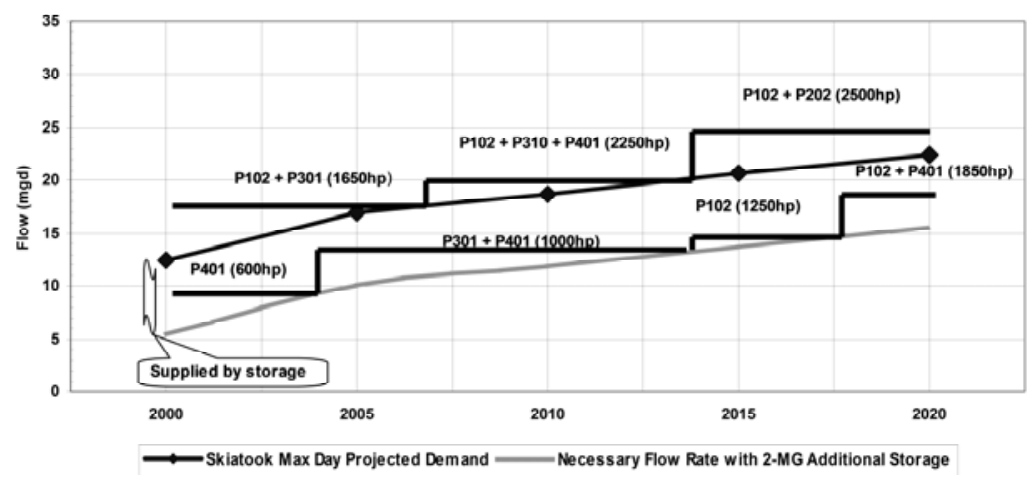

Figure 14.9 Additional 2 MG storage.

A second tank essentially doubled the system storage volume and provided additional safety margin during system maintenance and downtime. In addition, the SRWCS system has recently been experiencing the presence of Asian clam in the lake water. These clams grow to be approximately $40 \mathrm{~mm}$ in size and can cause problem to the downstream equipment. Though the strainer at the pump station is designed to remove solids $4 \mathrm{~mm}$ or larger, small larva can escape through the strainer and grow and attach to the pipe interior. During high flow conditions, they get dislodged from the pipe wall. With the addition of a second tank, the piping configuration was modified as shown in Figure 14.10 to allow a place for these clams to settle prior to reaching the down stream plants. The tanks are located at the highest point along the pipe alignment sufficiently away from the pump station. It is noted that the Surge 2000 software is not capable of directly modeling this configuration; therefore, the two tank configuration has to be modeled as one tank with an equivalent diameter and the same height. 


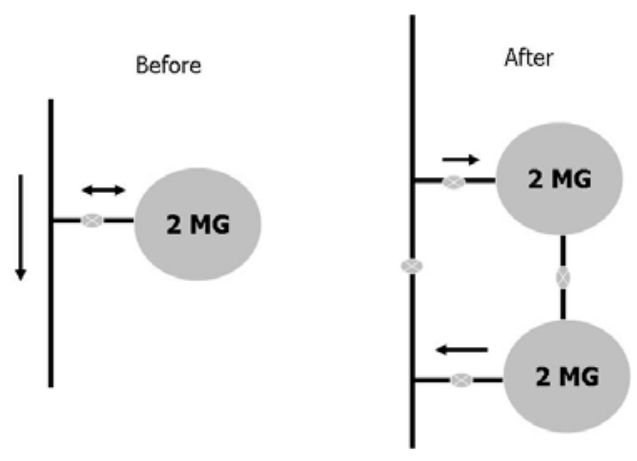

Figure 14.10 Tank piping alternate configuration.

\subsection{Conclusions}

With the advent of user friendly computer software, the analysis of transient flow in pipes can be effectively performed to establish design parameters that will ensure proper operation of the system. In order to effectively use the computer model, it must be properly calibrated using actual system data so the model reasonably computes the system behavior. A properly calibrated computer model is not only an invaluable tool to achieve proper system design but can help to optimize the system performance and reduce operational cost.

\section{Acknowledgment}

The author is grateful for the assistance and cooperation provided by the staff of the cities of Sapulpa and Sand Springs. Special thanks are also due to Jon Nelson, P.E., Neill Pullium, P.E. of Tetra Tech FHC for providing system schematics, Ryan Mittasch, P.E., of Tetra Tech FHC for gathering the field data, Chip Cohrs, P.E., of Tetra Tech FHC for assistance during field verification, and Matt Kesner, the station operator, for assistance during data gathering activities. 


\section{References}

Concepts of Water Hammer \& Air Entrapment in the Filling \& Testing of Pipelines, Recommendation Resulting from a Joint Research Effort of the Colorado State University Hydraulic Laboratory, J-M Pipe Manufacturing Company, Inc., 1051 Sperry Road, Stockton, CA 95206

Joseph R. Kroon, Michael A. Stoner, and William A. Hunt. Water Hammer: Causes and Effects, American Water Works Journal, November 1984.

Z. Michael Lehlow, Ph.D., Water Hammer, Tech Brief, National Drinking Water Clearing House Fact, WWW.NDWC.WVU.EDU.

Report, Skiatook Raw Water Conveyance System Pump Station Improvements, 2000, FHC Inc., 5416 S. Yale, Suite 400, Tulsa, OK 74135.

Report, Skiatook Raw Water Conveyance System Capacity Evaluation Report, 2001, FHC In., 5416 S. Yale, Suite 400, Tulsa, OK 74135.

Haestad, Walski, Chase, Savic, Grayman, Beckwith, and Koelle, Advanced Water Distribution Modeling and Management, First Edition, Pub by Haestad Press, ISBN: 0-9714141-2-2, Chapter 13.

Schade, T. (2002). Quality Assurance Project Plan for SWMM Redevelopment; U.SEPA Office of Research and Development - Water Supply and Water Resources Division; Cincinnati, Ohio; November 27, 2002.

U.S. EPA (2002). SWMM Redevelopment Project Plan - Version 5; U.S.EPA Office of Research and Development - Water Supply and Water Resources Division; Cincinnati, Ohio; February 19, 2002.

User Manual and Documentation, Pipe 2000, KY Pipe, LLC Software Center, www.kypipe.com. 
